\title{
Hemispherotomy in children with electrical status epilepticus of sleep
}

\author{
Anna Jeong, MD, ${ }^{1}$ Jennifer Strahle, MD, ${ }^{2}$ Ananth K. Vellimana, MD, ${ }^{2}$ \\ David D. Limbrick Jr., MD, PhD, ${ }^{2}$ Matthew D. Smyth, MD, ${ }^{2}$ and Mary Bertrand, MD1 \\ Departments of ${ }^{1}$ Neurology and ${ }^{2}$ Neurological Surgery, Washington University School of Medicine, St. Louis, Missouri
}

\begin{abstract}
OBJECTIVE Electrical status epilepticus of sleep (ESES) is a rare electrographic pattern associated with global regression, which is often poorly responsive to traditional epilepsy treatments and can have a devastating and permanent neurocognitive outcome. The authors analyzed clinical, electroencephalographic, and neuropsychological outcomes in 9 patients with refractory ESES treated with functional hemispherotomy to illustrate the wide clinical spectrum associated with the disease and explore the role of hemispherotomy in its treatment.
\end{abstract}

METHODS During the period between 2003 and 2015, 80 patients underwent hemispherotomy at the authors' institution. Video electroencephalography (EEG) reports were reviewed for ESES or continuous spikes and waves during sleep (CSWS). Patients with preoperative ESES (> 85\% slow-wave sleep occupied by spike waves), a unilateral structural lesion amenable to surgery, and more than 6 months of follow-up data were included in the analysis. Clinical data, EEG recordings, neuropsychological testing, and parental and clinician reports were retrospectively reviewed.

RESULTS Nine patients were eligible for study inclusion. Age at seizure onset ranged from birth to 4.2 years (mean 1.9 years), age at ESES diagnosis ranged from 3.5 to 8.8 years (mean 6.0 years), and age at hemispherotomy ranged from 3.7 to 11.5 years (mean 6.8 years). All patients had drug-resistant epilepsy. The duration of epilepsy prior to hemispherotomy ranged from 2.7 to 8.9 years (mean \pm SD, $5.0 \pm 2.2$ years). Engel Class I seizure outcome was observed in all 9 children, with a mean follow-up of 3.0 years (range $0.5-6.1$ years). Hemispherotomy terminated ESES in 6 of 6 patients with available postoperative sleep EEG. All children had preoperative neuropsychological impairments. Developmental regression was halted postoperatively, but none of the children returned to their original pre-ESES baseline. Four children demonstrated academic gains, 2 of whom transitioned to mainstream classes.

CONCLUSIONS Children with drug-resistant ESES and a unilateral structural lesion should be evaluated for hemispherotomy as they may experience the cessation of seizures, termination of ESES, and improvement in neuropsychological status.

http://thejns.org/doi/abs/10.3171/2016.8.PEDS16319

KEY WORDS electrical status epilepticus of sleep; ESES; continuous spikes and waves during sleep; CSWS; epilepsy surgery

$\mathrm{E}$ LeCTRICAL status epilepticus of sleep (ESES) is an electrographic pattern characterized by near continuous spike-wave discharges in non-rapid eye movement (REM) sleep. ${ }^{21}$ This electrographic pattern was first described in 1971 by Tassinari and colleagues, who described 6 children in whom electroencephalography (EEG) recording was characterized by a "spectacular" increase of continuous generalized spike and wave discharges during slow-wave sleep..$^{15}$ Several years later, Tassinari and colleagues ${ }^{20}$ first introduced the term "encephalopathy related to electrical status epilepticus during slow wave sleep," imparting equal weight to the encephalopathy or "mental deterioration" that was often observed in individuals displaying such an EEG pattern. In 1989, the International League Against Epilepsy (ILAE) recognized the syndrome and adopted the terminology "epileptic encephalopathy with continuous spikes and waves during sleep" (CSWS), including in its description the characteristic EEG pattern, the usually benign evolution of seizures, and the guarded prognosis due to the appearance of neuropsychological disorders. ${ }^{2}$

Since the disease's original description in 1971, no clear

ABBREVIATIONS CSWS = continuous spikes and waves during sleep; EEG = electroencephalography; ESES = electrical status epilepticus of sleep; FSIQ = Full Scale $I Q ; P I Q=$ Performance IQ; VIQ = Verbal IQ; VMI = visual-motor integration; VNS = vagus nerve stimulator; WPPSI = Wechsler Preschool and Primary Scale of Intelligence. SUBMITTED June 2, 2016. ACCEPTED August 16, 2016.

INCLUDE WHEN CITING Published online October 28, 2016; DOI: 10.3171/2016.8.PEDS16319. 
consensus has emerged on its underlying pathophysiology, diagnostic criteria (for example, the requisite percentage of the sleep record occupied by spikes), or optimal treatment. The syndrome is heterogeneous with various etiologies described including hydrocephalus, cortical brain malformations, perinatal vascular injuries, thalamic injury, and focal epilepsies of childhood such as rolandic epilepsy. 1,710,17,19,22 Various antiseizure drugs and immunomodulatory therapies have been used in the treatment of ESES, but the response to treatment is often disappointing as medications can be ineffective or incompletely effective in improving the EEG and/or neurocognitive profile..$^{10}$ Permanent cognitive impairments result in an estimated $40 \%-60 \%$ of children with ESES..$^{10,12}$ In the current study we report the preoperative and postoperative findings in a series of children with ESES and unilateral brain lesions who underwent hemispherotomy for refractory epilepsy. We illustrate the wide clinical spectrum associated with ESES and explore the role of hemispherotomy in its treatment.

\section{Methods \\ Patient Selection}

During the period between 2003 and 2015, 80 patients underwent hemispherotomy at St. Louis Children's Hospital. Video EEG reports were reviewed for ESES or CSWS. Preoperative and postoperative EEG recordings were then reanalyzed by one of the authors (A.J.). We included in our analysis those patients who had a preoperative EEG with $>85 \%$ of slow-wave sleep occupied by spike waves and for whom postoperative follow-up data for more than 6 months were available. Approval from the Washington University institutional review board for human research (Human Research Protection Office) was obtained prior to this retrospective study.

\section{Clinical Data Review}

Clinical details such as sex, age, handedness, neurological examination including presence or absence of hemiparesis, birth history, developmental history, epilepsy history including age at seizure onset, seizure types, seizure frequency, antiseizure medications, and previous surgeries were extracted from pediatric neurology clinic, pediatric neurosurgery clinic, and medical center records.

Other testing included preoperative and postoperative scalp EEG, MRI, FDG-PET, pathology, and preoperative and postoperative neuropsychological testing, if available.

Records from pediatric neurology and neurosurgery clinic visits were reviewed to assess postoperative outcome. Seizure outcome was assessed using the Engel seizure outcome classification. ${ }^{23}$ Postoperative cognitive outcomes were extracted from clinical notes and, when available, from postoperative neuropsychological evaluations.

\section{Results \\ Clinical Presentation}

Nine patients (4 male and 5 female) met the study inclusion criteria. Age at seizure onset ranged from birth to 4 years 2 months (mean $\pm \mathrm{SD}, 1.9 \pm 1.7$ years). Two patients had a history of infantile spasms. At the time of surgery, all 9 patients had focal seizures with variable features including dyscognitive symptoms, motor symptoms, and evolution to bilateral convulsive seizures. Additionally, 1 patient was having clusters of myoclonic seizures. All patients were having seizures at least once per week, with 6 of the 9 patients having multiple daily seizures.

All patients had had a poor response to antiseizure drugs, and all were taking 2-5 antiseizure medications at the time of surgery. Two patients had a vagus nerve stimulator (VNS) in place at the time of hemispherotomy, with both individuals having undergone VNS implantation prior to treatment at our institution. None of the patients were on the ketogenic diet at the time of surgery, although 1 patient had attempted the diet without success. Patient demographics are summarized in Table 1.

\section{Neuroimaging and Neuropathology}

All of the patients in our series demonstrated unilateral cortical abnormalities. Three patients (Cases 1, 3, and 5) had MRI evidence of a perinatal infarct with unilateral encephalomalacia. The remaining patients demonstrated malformations of cortical development on neuroimaging, with pathological analysis revealing polymicrogyria in 4 patients (Cases 2, 4, 6, and 8), focal cortical dysplasia Type IIB in 1 patient (Case 7), and hemimegalencephaly in 1 patient (Case 9). In all 4 patients with polymicrogyria, the frontal and parietal lobes were predominantly affected. The FDG-PET studies were concordant in all but 1 patient (Case 4), who demonstrated increased tracer uptake in the structurally affected hemisphere presumably secondary to electrographic seizures recorded immediately prior to tracer injection.

\section{Preoperative and Postoperative Developmental Assessment and Neuropsychological Testing}

Five patients had delayed early language development ranging from mild speech delay to no language acquisition in 1 patient (Case 9). Four patients reportedly had normal early language development. Of these 4,1 patient (Case 6) had an abrupt regression of language over a period of several weeks at the onset of seizures (age 3 years) and was nonverbal at the time of surgery (age 7 years 2 months). Another patient (Case 8) had a more gradual regression of language over a period of several years beginning with the onset of seizures (age 4 years) and was minimally verbal, speaking infrequently in 1- to 2 -word phrases at the time of surgery (age 8.7 years). All of the remaining patients demonstrated language impairment at the time of surgery. All patients had varying degrees of hemiparesis at the time of surgery.

Behavioral issues ranging from emotional lability and inattention to oppositional behaviors were reported in 5 of 9 patients, with 1 patient (Case 7) requiring inpatient psychiatric admission for aggression.

Preoperative neuropsychological testing results were available for 7 of the 9 patients. In 4 patients (Cases 2, 3, 5, and 7), attentional or behavioral issues limited the testing sessions. One patient (Case 9) was severely impaired and only able to participate in the Bayley Scales of Infant and Toddler Development despite an age of 8 years at the time 
TABLE 1. Clinical and pathological characteristics of 9 patients with ESES

\begin{tabular}{|c|c|c|c|c|c|c|c|}
\hline $\begin{array}{l}\text { Case } \\
\text { No. }\end{array}$ & $\begin{array}{l}\text { Handedness/ } \\
\text { Sex }\end{array}$ & $\begin{array}{l}\text { Age } \\
\text { at } \\
\text { 1st } \\
\text { Seizure }\end{array}$ & $\begin{array}{l}\text { Seizure } \\
\text { Types } \\
\text { (preop } \\
\text { frequency) }\end{array}$ & $\begin{array}{l}\text { Age at } \\
\text { 1st EEG } \\
\text { Documenting } \\
\text { ESES }\end{array}$ & $\begin{array}{l}\text { Side of } \\
\text { Op } \\
\text { (age at } \\
\text { op) }\end{array}$ & Pathology & $\begin{array}{c}\text { Engel } \\
\text { Outcome } \\
\text { Class } \\
\text { (duration } \\
\text { of FU) }\end{array}$ \\
\hline 1 & $\mathrm{Lt} / \mathrm{M}$ & 6 mos & $\begin{array}{l}\text { Focal } w / \text { dyscognitive features (3/day } \\
\text { to } 1 / w k)\end{array}$ & 7 yrs 9 mos & $\begin{array}{l}\text { Lt }(8 \text { yrs } 9 \\
\text { mos) }\end{array}$ & Cystic cortical \& white matter loss & I (1.9 yrs) \\
\hline 2 & $\mathrm{Lt} / \mathrm{F}$ & $\begin{array}{r}2 \text { yrs } 6 \\
\text { mos }\end{array}$ & $\begin{array}{l}\text { Focal w/ motor/dyscognitive features } \\
(2 / w k)\end{array}$ & 5 yrs $1 \mathrm{mo}$ & $\begin{array}{l}\text { Lt (11 yrs } \\
6 \text { mos) }\end{array}$ & Polymicrogyria & I (2.6 yrs) \\
\hline 3 & $\mathrm{Lt} / \mathrm{F}$ & 3 mos & $\begin{array}{l}\text { Focal w/ motor/dyscognitive features } \\
(0-10 / \text { day), focal w/ evolution to } \\
\text { bilat convulsive }(0-1 / \mathrm{mo})\end{array}$ & 4 yrs 8 mos & $\begin{array}{l}\text { Lt }(4 \text { yrs } 9 \\
\text { mos) }\end{array}$ & $\begin{array}{l}\text { Marked neuronal \& white matter loss } \\
\quad \& \text { gliosis }\end{array}$ & I (0.5 yr) \\
\hline 4 & $\mathrm{Rt} / \mathrm{F}$ & $\begin{array}{r}2 \text { yrs } 6 \\
\text { mos }\end{array}$ & $\begin{array}{l}\text { Focal w/ motor/dyscognitive features } \\
\text { ( } 50-300 / \text { day), focal w/ evolution to } \\
\text { bilat convulsive (rare) }\end{array}$ & 5 yrs 2 mos & $\begin{array}{l}\text { Rt (5 yrs } \\
\quad 3 \text { mos) }\end{array}$ & Polymicrogyria & I (6.1 yrs) \\
\hline 5 & $\mathrm{Lt} / \mathrm{F}$ & 0 mos & $\begin{array}{l}\text { Focal w/ motor/dyscognitive features } \\
(1-2 / \text { day })\end{array}$ & 3 yrs 6 mos & $\begin{array}{l}\text { Lt }(3 \text { yrs } 8 \\
\text { mos) }\end{array}$ & Astrocytosis, neuron loss & I (4.1 yrs) \\
\hline 6 & $\mathrm{Rt} / \mathrm{M}$ & 3 yrs & $\begin{array}{l}\text { Focal } w / \text { dyscognitive features (3-4/ } \\
\text { day), focal w/ evolution to bilat } \\
\text { convulsive ( } 2 \text { lifetime) }\end{array}$ & 4 yrs 2 mos & $\begin{array}{l}\text { Rt (7 yrs } \\
2 \text { mos) }\end{array}$ & Polymicrogyria & I (4.6 yrs) \\
\hline 7 & $\mathrm{Rt} / \mathrm{M}$ & $\begin{array}{r}4 \text { yrs } 2 \\
\text { mos }\end{array}$ & $\begin{array}{l}\text { Focal w/ motor/dyscognitive features } \\
\text { (3-4/day), focal w/ evolution to bilat } \\
\text { convulsive }(0-1 / \mathrm{mo})\end{array}$ & 8 yrs 10 mos & $\begin{array}{l}\text { Rt (8 yrs } \\
11 \\
\text { mos) }\end{array}$ & Focal cortical dysplasia Type IIB & I (4.7 yrs) \\
\hline 8 & $\mathrm{Rt} / \mathrm{M}$ & 4 yrs & $\begin{array}{l}\text { Focal } w / \text { dyscognitive features } \\
\quad(30-40 / \text { day })\end{array}$ & 8 yrs 8 mos & $\begin{array}{l}\text { Rt (8 yrs } \\
\quad 8 \text { mos) }\end{array}$ & $\begin{array}{l}\text { Complex malformation involving poly- } \\
\text { microgyria, cortical dyslamination, } \\
\text { superficial neuronal heterotopias, } \\
\text { \& white matter neurons }\end{array}$ & I (1.8 yrs) \\
\hline 9 & $\mathrm{Rt} / \mathrm{F}$ & 0 mos & $\begin{array}{l}\text { Focal w/ dyscognitive features (1-2/ } \\
\text { mo), myoclonic (clusters, } 5-20 / \text { day) }\end{array}$ & $8 \mathrm{yrs} 8 \mathrm{mos}$ & Rt (9 yrs) & $\begin{array}{l}\text { Dysplastic megalencephaly, scat- } \\
\text { tered hamartias }\end{array}$ & I (1.0 yrs) \\
\hline
\end{tabular}

$F U=$ follow-up.

of testing. Full Scale IQ (FSIQ) could be calculated in 4 patients, who fell in the moderately impaired (FSIQ 41, Case 8), mildly impaired (FSIQ 63, Case 3), and normal (FSIQ 74, Case 5; FSIQ 80, Case 7) ranges.

Three patients underwent formal postoperative neuropsychological testing. The patient in Case 4 demonstrated an improvement in Performance IQ (PIQ) from 51 to 67 on the Wechsler Preschool and Primary Scale of Intelligence (WPSSI), with otherwise stable scores in other domains. The patient in Case 7 had an improvement in Verbal IQ (VIQ) from 88 to 95 on the WPSSI but had a decline in PIQ from 77 to 62 and visual-motor integration (VMI) from 72 to 66. Notably, the patient in Case 7 had severe preoperative emotional and behavioral issues, which, according to his parents, improved significantly after surgery. One subject (Case 9) remained severely impaired without significant changes on the Bayley Scales of Infant and Toddler Development. Of those patients who did not undergo postoperative testing, 2 patients (Cases 2 and 5) reportedly had significant developmental and academic improvements, with eventual placement into mainstream classes. Additionally, 2 patients (Cases 1 and 8) were, according to their parents, displaying marked improvement academically, and neuropsychological testing was declined by the family of 1 of these patients because he was doing so well. One patient (Case 6) remained nonverbal postoperatively and was only able to communicate using an augmentative and alternative picture-communication device. Preoperative and postoperative neuropsychological testing results are summarized in Table 2.

\section{Preoperative and Postoperative EEG}

Preoperative EEG showed ESES in all patients. The age at which ESES was diagnosed ranged from 3.5 to 8.8 years (mean $6.0 \pm 2.0$ years). Time between the first seizure and the electrographic diagnosis of ESES ranged from 1.2 to 8.7 years (mean $4.4 \pm 2.3$ years). In 6 patients, the epileptiform discharges were bilateral but asymmetrical, appearing either voltage or frequency maximal in the structurally affected hemisphere. In 3 patients (Cases 1, 2, and 4), the epileptiform discharges were symmetric and maximal bifrontally.

Postoperative sleep EEG was available for 6 of 9 patients, none of whom showed persistent ESES. Of these 6 patients, 2 had no residual epileptiform discharges (Fig. 1). Of the 3 patients with only awake EEG studies available, all 3 had residual unilateral epileptiform discharges during the awake state. Preoperative and postoperative EEG findings are summarized in Table 2. 
TABLE 2. Electroencephalography and neuropsychological results of 9 patients with ESES

\begin{tabular}{|c|c|c|c|c|}
\hline $\begin{array}{l}\text { Case } \\
\text { No. }\end{array}$ & $\begin{array}{l}\text { Preop EEG } \\
\text { Spike Source }\end{array}$ & $\begin{array}{l}\text { Postop Epileptiform } \\
\text { Findings }\end{array}$ & $\begin{array}{c}\text { Age at Testing: Preop } \\
\text { Neuropsychological Assessment }\end{array}$ & $\begin{array}{c}\text { Age at Testing: Postop } \\
\text { Neuropsychological Assessment }\end{array}$ \\
\hline 1 & $\begin{array}{l}\text { Bilat, maximal in bifron- } \\
\text { tal regions }\end{array}$ & $\begin{array}{l}\text { Occasional It frontal sharp } \\
\text { waves, at times w/ a } \\
\text { voltage field extending } \\
\text { to rt hemisphere }\end{array}$ & $\begin{array}{l}\text { Formal testing results unavailable (performed } \\
\text { at outside institution); clinical notes state } \\
\text { "delayed response time when speaking, } \\
\text { tangential in speech with poor articulation" }\end{array}$ & $\begin{array}{l}\text { Formal testing not done; family } \\
\text { declined testing as the patient was } \\
\text { reportedly markedly improved \& } \\
\text { making steady progress in school }\end{array}$ \\
\hline 2 & $\begin{array}{l}\text { Bilat, maximal in bifron- } \\
\text { tal regions }\end{array}$ & $\begin{array}{l}\text { Frequent It frontal, It } \\
\text { parietal, \& It temporal } \\
\text { spikes, at times w/ a } \\
\text { voltage field extending } \\
\text { to rt hemisphere }\end{array}$ & $\begin{array}{l}5 \text { yrs } 1 \text { mo: limited testing due to poor coopera- } \\
\text { tion, FSIQ could not be calculated; SB5 Fluid } \\
\text { Reasoning SS: 7, PPVT-4 total score: } 77 \text {, } \\
\text { VMI: } 82 \text {, ABAS-II General Adaptive Compos- } \\
\text { ite SS: } 50\end{array}$ & $\begin{array}{l}\text { Formal testing not done; family } \\
\text { reported significant speech/lan- } \\
\text { guage improvement w/ transition } \\
\text { to mainstream classes }\end{array}$ \\
\hline 3 & $\begin{array}{l}\text { Bilat, maximal in It } \\
\text { frontocentral \& It cen- } \\
\text { troparietal regions }\end{array}$ & $\begin{array}{l}\text { No epileptiform dis- } \\
\text { charges }\end{array}$ & $\begin{array}{l}4 \text { yrs } 6 \text { mos: limited testing due to emotional } \\
\text { lability; WPPSI-IV FSIQ: } 63, \text { VCl: } 71, \text { VSI: } 58 \text {, } \\
\text { VMI: } 93\end{array}$ & Formal testing not done \\
\hline 4 & $\begin{array}{l}\text { Bilat, maximal in bifron- } \\
\text { tal regions }\end{array}$ & $\begin{array}{l}\text { Frequent rt centroparietal } \\
\text { spikes (wake only) }\end{array}$ & $\begin{array}{l}5 \text { yrs } 2 \text { mos: WPPSI-III VIQ: 72, PIQ: 51, VMI: } \\
\text { 62, VABS composite: } 58\end{array}$ & $\begin{array}{l}5 \text { yrs } 10 \text { mos: WPPSI-III VIQ: 74, PIQ: } \\
\text { 67, VMI: 65; VABS composite: } 61\end{array}$ \\
\hline 5 & $\begin{array}{l}\text { Bilat, maximal in It } \\
\text { posterior region }\end{array}$ & $\begin{array}{l}\text { Frequent It frontocentral } \\
\text { \& It mid- to posterior } \\
\text { temporal spikes (wake } \\
\text { only) }\end{array}$ & $\begin{array}{l}3 \text { yrs } 6 \text { mos: limited testing due to fleeting } \\
\text { attention \& inconsistent responses during } \\
\text { testing; WPPSI-III FSIQ: 74; VIQ: 88, PIQ: } \\
\text { 63, VMI: } 77\end{array}$ & $\begin{array}{l}\text { Formal testing not done; family } \\
\text { reported significant academic } \\
\text { improvement w/ eventual transition } \\
\text { into mainstream classes }\end{array}$ \\
\hline 6 & $\begin{array}{l}\text { Bilat, maximal in rt } \\
\quad \text { frontal \& rt centro- } \\
\text { temporal regions }\end{array}$ & $\begin{array}{l}\text { Frequent It central spikes, } \\
\text { occasional rt central } \\
\text { spikes }\end{array}$ & Formal testing not done, nonverbal & Formal testing not done, nonverbal \\
\hline 7 & $\begin{array}{l}\text { Bilat, maximal in rt } \\
\text { hemisphere }\end{array}$ & $\begin{array}{l}\text { Occasional rt frontal } \\
\text { spikes }\end{array}$ & $\begin{array}{l}8 \text { yrs } 9 \text { mos: limited testing due to poor attention; } \\
\text { WASI FSIQ: } 80, \text { VIQ: } 88, \text { PIQ: } 77, \text { VMI: } 72\end{array}$ & $\begin{array}{l}10 \text { yrs } 7 \text { mos: WASI FSIQ: not re- } \\
\text { ported, VIQ: 95, PIQ: } 62 \text {, VMI: } 66\end{array}$ \\
\hline 8 & $\begin{array}{l}\text { Bilat, maximal in rt fron- } \\
\text { totemporal region }\end{array}$ & $\begin{array}{l}\text { No epileptiform dis- } \\
\text { charges }\end{array}$ & $\begin{array}{l}8 \text { yrs } 8 \text { mos: SB5 FSIQ: 41, verbal: } 43 \text {, non- } \\
\text { verbal: 44; PPVT-4: 41, VMI: 58, ABAS-II } \\
\text { General Adaptive Composite SS: } 58\end{array}$ & $\begin{array}{l}\text { Formal testing not done; family } \\
\text { reported academic improvements }\end{array}$ \\
\hline 9 & $\begin{array}{l}\text { Bilat, maximal in rt } \\
\text { posterior region }\end{array}$ & $\begin{array}{l}\text { Nearly continuous rt } \\
\text { hemispheric spikes } \\
\text { (wake only) }\end{array}$ & $\begin{array}{l}8 \text { yrs } 8 \text { mos: Bayley-III cognitive: } 8 \text { mos, } \\
\text { receptive language: } 2-3 \text { mos, expressive } \\
\text { language: } 2 \text { mos, fine motor: } 5-6 \text { mos }\end{array}$ & $\begin{array}{l}9 \text { yrs } 11 \text { mos: Bayley-III cognitive: } \\
7 \text { mos, receptive language: } 5-6 \\
\text { mos, expressive language: } 2-3 \\
\text { mos, fine motor: } 6 \text { mos }\end{array}$ \\
\hline
\end{tabular}

ABAS = Adaptive Behavior Assessment System; Bayley-III = Bayley Scale of Infant and Toddler Development, 3rd edition; FSIQ = Full Scale IQ; PIQ = Performance IQ; PPVT-4 = Peabody Picture Vocabulary Test, 4th edition; SB5 = Stanford-Binet Intelligence Scales, 5th edition; SS = scaled score; VABS = Vineland Adaptive Behavioral Scales; $\mathrm{VCI}=$ Verbal Comprehension Index; VIQ = Verbal IQ; VMI = developmental test of visual-motor integration; VSI = Visual Spatial Index; WASI = Wechsler Abbreviated Scale of Intelligence; WPPSI-III = Wechsler Preschool and Primary Scale of Intelligence, 3rd edition; WPPSI-IV = WPPSI, 4th edition.

\section{Operative and Seizure Outcome}

All patients underwent peri-insular functional hemispherotomy, as described elsewhere. ${ }^{11}$ Age at surgery ranged from 3.7 to 11.5 years (mean $6.8 \pm 2.1$ years). The duration of epilepsy prior to hemispherotomy ranged from 2.7 to 8.9 years (mean $5.0 \pm 2.2$ years). The only postoperative complication was an episode of cerebrospinal fluid otorrhea in 1 patient (Case 5), which resolved with lumbar drainage. The mean follow-up was 3.0 years (range 0.56.1 years). All 9 patients were seizure free (Engel Class I) at the last follow-up. One patient (Case 7) began having a new spell type approximately 3 years after surgery, which was markedly different from his preoperative seizures and thought to represent nonepileptic events.

\section{Discussion}

This is the largest series of patients with ESES who have undergone hemispherotomy reported to date. Our pa- tients had uniformly positive seizure outcomes, with 9 of 9 patients having Engel Class I seizure outcomes over a follow-up period ranging from 6 months to 6.1 years (mean 3.0 years). Positive seizure outcomes have been reported in children with ESES and structural lesions who have undergone epilepsy surgery, including hemispherotomy and focal resection. ${ }^{8-10,13,16}$

All of our patients demonstrated language and motor impairments prior to surgery. Available postoperative neuropsychological testing demonstrated either slight improvement or mixed results. Although formal neuropsychological testing did not show marked improvement, parental reports indicated that 4 patients demonstrated significant developmental and academic gains, with 2 patients transitioning to mainstream classes. No patients demonstrated continued regression of skills. Additionally, attentional improvements were noted by parental reports, a finding in line with previous case studies. ${ }^{9}$

Postoperative EEG showed the resolution of ESES in 

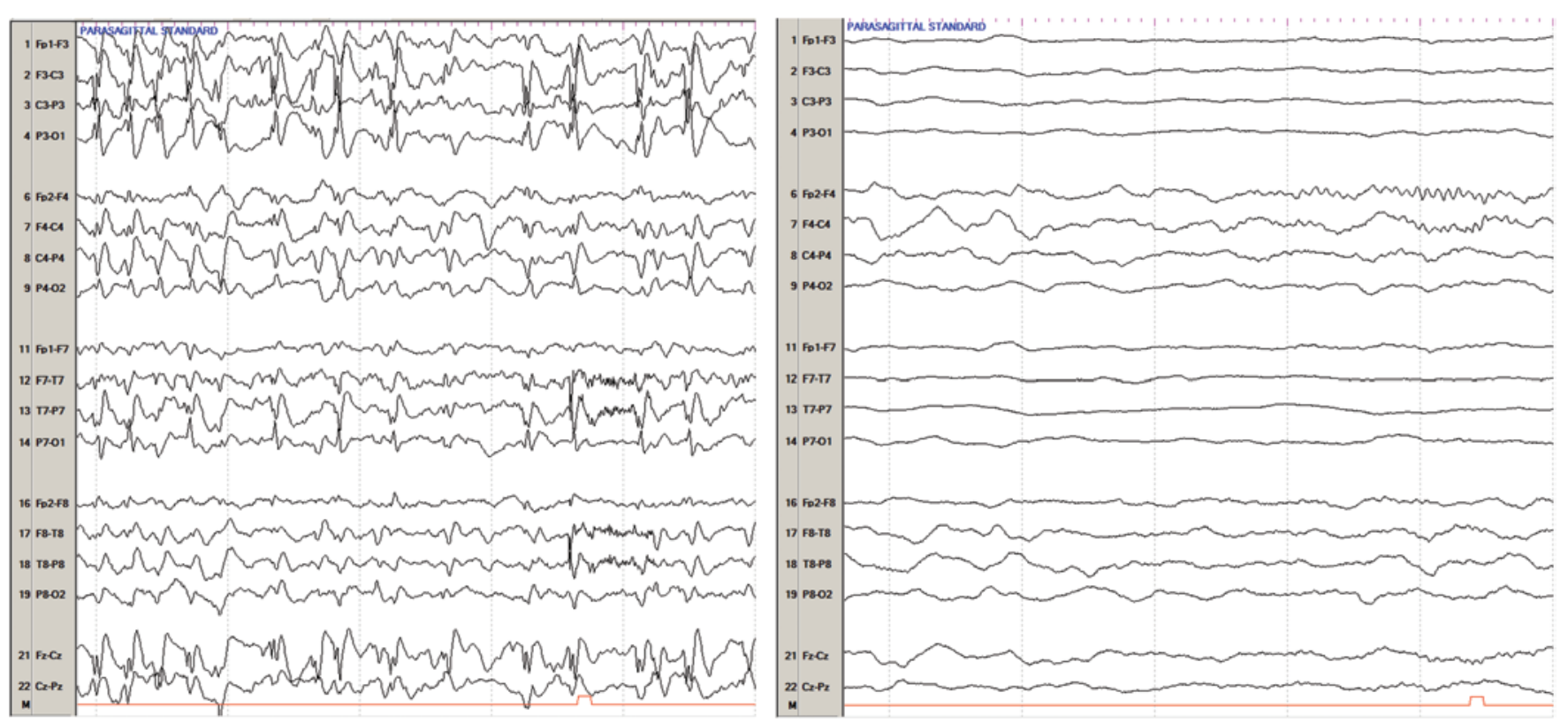

FIG. 1. Case 3. Preoperative EEG (left) compared with postoperative EEG (right). Note that the display sensitivity has been set to $15 \mu \mathrm{V} / \mathrm{mm}$ and the time scale is 10 seconds per page. Figure is available in color online only.

all patients with available sleep EEG (6 patients). Moreover, 2 patients had complete resolution of epileptiform discharges during both the wake and the sleep states. One patient continued to have nearly continuous unilateral spikes over the disconnected hemisphere while awake, and sleep EEG was not performed. This patient was severely impaired and demonstrated no appreciable change on postoperative neuropsychological testing.

The underlying etiologies included perinatal infarct $(3$ patients) or malformations of cortical development including polymicrogyria (4 patients), hemimegalencephaly (1 patient), and focal cortical dysplasia (1 patient), as confirmed by pathology. Although the underlying pathophysiology of ESES is not fully understood, structural lesions such as early vascular insults and developmental lesions have been shown to be associated with ESES. ${ }^{5}$ Of the migrational disorders, polymicrogyria has specifically been shown to manifest with ESES, ${ }^{6}$ which is in line with our findings. In our series, children with an underlying perinatal infarct tended to present with seizures at a younger age (mean 3.0 months, range birth to 6.0 months) as compared to those with an underlying malformation of cortical development (mean 2.7 years, range birth to 4.2 years). However, no difference was observed in the age at diagnosis of ESES (that is, the first EEG documenting ESES). Several patients had their first EEG documenting ESES close to the time of their surgery, with the lag time ranging from several weeks to 2 months prior to surgery. However, we recognize that the duration of ESES was probably longer given that the electrographic diagnosis of ESES is highly dependent on the timing and frequency of EEG studies including sleep EEG studies.

Loddenkemper et al. ${ }^{13}$ studied 6 patients with ESES who underwent hemispherotomy and found that postoperative neuropsychological outcome was either stable or slightly improved in those with available testing. Peltola et al. ${ }^{16}$ described 2 children who underwent hemispherotomy, with 1 child having an improvement in cognitive outcome and 1 child having an initial decline at 6 months after the procedure, followed by a return to the preoperative level by 2 years post-hemispherotomy. Kallay et al. ${ }^{9}$ performed sequential neuropsychological testing in a child diagnosed with ESES treated with hemispherotomy; the authors reported gradual but incomplete cognitive recovery with residual moderate cognitive disability. Two other case reports ${ }^{1,10}$ describing children with ESES and structural lesions who underwent hemispherotomy have similarly shown an improvement in cognitive outcome as compared with the preoperative baseline. Taken together, these smaller series and case reports have presented a positive but guarded picture, one in which hemispherotomy may improve cognitive outcomes but does not fully reverse the regression or loss of milestones sustained during the period of ESES. Our results were similar in that postoperative neuropsychological testing did not demonstrate marked improvements. However, the parental reports were positive, with significant academic improvements noted in 4 children, 2 of whom were able to transition to mainstream classes.

The duration of epilepsy prior to surgery ranged from 2.7 to 8.9 years (mean $5.0 \pm 2.2$ years). In our small cohort, we were unable to determine whether a longer duration of epilepsy prior to surgery negatively impacted postoperative neurocognitive outcome. However, prior studies have demonstrated a negative association between a longer duration of epilepsy and postoperative neurocognitive improvements. ${ }^{4}$

Electrical status epilepticus of sleep is a rare childhood epilepsy syndrome that occurs only in the 1st decade of life. ${ }^{5}$ Due in part to the typically benign evolution of 
seizures and the resolution of the EEG pattern over time, the role of epilepsy surgery for ESES has been limited. Kramer et al. ${ }^{10}$ found that an ESES duration longer than 18 months was associated with residual cognitive deficits, whereas no residual intellectual deficits were seen in most patients with an ESES period shorter than 13 months. Similarly, Pera et al. ${ }^{17}$ and Seegmüller et al.$^{18}$ found that a longer duration of ESES was associated with a poorer cognitive prognosis, with both groups advocating an aggressive therapeutic approach to potentially prevent long-term cognitive and neuropsychological deterioration. Given the poor prognosis associated with this syndrome, we believe that all available treatment modalities, including epilepsy surgery, should at least be considered in the approach to ESES.

Although all of our patients had unilateral brain lesions, the preoperative sleep EEG demonstrated bilateral abnormalities in all cases. Three patients had symmetric, frontally predominant spike-wave discharges, whereas the remaining patients had asymmetrical but bilateral spikewave discharges. The underlying mechanism of ESES is unknown, but as noted by other authors, ${ }^{1,13}$ the resolution of ESES after epilepsy surgery supports the theory that the underlying pathogenesis of ESES is focal with presumed secondary bilateral synchrony.

Prior studies have shown that neurocognitive regression in ESES is typically seen between 5 and 6 years of age, with epilepsy onset preceding the regression by $1-2$ years. ${ }^{2,12}$ We propose that clinicians maintain a high level of suspicion and a low threshold for obtaining an overnight EEG study to evaluate for ESES in school-aged children with epilepsy and a structural lesion. Furthermore, if the structural lesion is shown to cause the epilepsy and ESES, timely epilepsy surgery evaluation and potentially resective surgery should be strongly considered.

Our series included only individuals with drug-resistant epilepsy, ESES, and a unilateral structural lesion. Another group to consider consists of those individuals with ESES and a unilateral structural lesion without active epilepsy. Traditionally, these individuals may not be considered epilepsy surgery candidates since their clinical seizures may be in remission. However, this is a unique group in which hemispherotomy and the arrest of ESES may prevent irreversible cognitive decline, and we believe that this group should at least be considered for epilepsy surgery.

The main limitations of our study include its retrospective nature, small sample size, and incomplete records. We recognize that the timing and frequency of data acquisition, particularly EEG studies, was not standardized. Because of the incomplete neuropsychological records, we relied heavily on parental and clinician reports to determine postoperative functional status. Various neuropsychological testing metrics were used, and testing was performed at various time points. Although postoperative EEG studies were obtained for all patients, these studies were incomplete since sleep EEG studies were not obtained in all patients.

Early epilepsy surgery has been shown to improve developmental outcomes in children, ${ }^{14}$ and children with ESES represent a particularly vulnerable group that has much to gain from early recognition of the syndrome and rapid intervention. In summary, hemispherotomy should be considered in refractory ESES as cognitive and behavioral improvements may be seen. Despite this study's limitations, it documents the largest group of patients with ESES to undergo hemispherotomy described to date.

\section{Conclusions}

This is the largest reported series of patients with ESES to have undergone hemispherotomy, with all patients having seizure remission at the last follow-up, postoperative developmental gains in a subset of patients, and behavioral and attentional improvements reported. In patients with a structural lesion and refractory ESES, epilepsy surgery, specifically hemispherotomy, should be considered as a potential treatment option.

\section{References}

1. Battaglia D, Veggiotti P, Lettori D, Tamburrini G, Tartaglione T, Graziano A, et al: Functional hemispherectomy in children with epilepsy and CSWS due to unilateral early brain injury including thalamus: sudden recovery of CSWS. Epilepsy Res 87:290-298, 2009

2. Commission on Classification and Terminology of the International League Against Epilepsy: Proposal for revised classification of epilepsies and epileptic syndromes. Epilepsia 30:389-399, 1989

3. Fernández IS, Peters JM, Hadjiloizou S, Prabhu SP, Zarowski M, Stannard KM, et al: Clinical staging and electroencephalographic evolution of continuous spikes and waves during sleep. Epilepsia 53:1185-1195, 2012

4. Freitag H, Tuxhorn I: Cognitive function in preschool children after epilepsy surgery: rationale for early intervention. Epilepsia 46:561-567, 2005

5. Galanopoulou AS, Bojko A, Lado F, Moshé SL: The spectrum of neuropsychiatric abnormalities associated with electrical status epilepticus in sleep. Brain Dev 22:279-295, 2000

6. Guerrini R, Genton P, Bureau M, Parmeggiani A, Salas-Puig X, Santucci M, et al: Multilobar polymicrogyria, intractable drop attack seizures, and sleep-related electrical status epilepticus. Neurology 51:504-512, 1998

7. Guzzetta F, Battaglia D, Veredice C, Donvito V, Pane M, Lettori D, et al: Early thalamic injury associated with epilepsy and continuous spike-wave during slow sleep. Epilepsia 46:889-900, 2005

8. Harvey AS, Cross JH, Shinnar S, Mathern GW: Defining the spectrum of international practice in pediatric epilepsy surgery patients. Epilepsia 49:146-155, 2008 (Erratum in Epilepsia 54:1140, 2013)

9. Kallay C, Mayor-Dubois C, Maeder-Ingvar M, Seeck M, Debatisse D, Deonna T, et al: Reversible acquired epileptic frontal syndrome and CSWS suppression in a child with congenital hemiparesis treated by hemispherotomy. Eur J Paediatr Neurol 13:430-438, 2009

10. Kramer U, Sagi L, Goldberg-Stern H, Zelnik N, Nissenkorn A, Ben-Zeev B: Clinical spectrum and medical treatment of children with electrical status epilepticus in sleep (ESES). Epilepsia 50:1517-1524, 2009

11. Limbrick DD, Narayan P, Powers AK, Ojemann JG, Park TS, Bertrand M, et al: Hemispherotomy: efficacy and analysis of seizure recurrence. J Neurosurg Pediatr 4:323-332, 2009

12. Liukkonen E, Kantola-Sorsa E, Paetau R, Gaily E, Peltola M, Granström ML: Long-term outcome of 32 children with encephalopathy with status epilepticus during sleep, or ESES syndrome. Epilepsia 51:2023-2032, 2010

13. Loddenkemper T, Cosmo G, Kotagal P, Haut J, Klaas P, Gup- 
ta A, et al: Epilepsy surgery in children with electrical status epilepticus in sleep. Neurosurgery 64:328-337, 2009

14. Loddenkemper T, Holland KD, Stanford LD, Kotagal P, Bingaman W, Wyllie E: Developmental outcome after epilepsy surgery in infancy. Pediatrics 119:930-935, 2007

15. Patry G, Lyagoubi S, Tassinari CA: Subclinical "electrical status epilepticus" induced by sleep in children. A clinical and electroencephalographic study of six cases. Arch Neurol 24:242-252, 1971

16. Peltola ME, Liukkonen E, Granström ML, Paetau R, Kantola-Sorsa E, Valanne L, et al: The effect of surgery in encephalopathy with electrical status epilepticus during sleep. Epilepsia 52:602-609, 2011

17. Pera MC, Brazzo D, Altieri N, Balottin U, Veggiotti P: Longterm evolution of neuropsychological competences in encephalopathy with status epilepticus during sleep: a variable prognosis. Epilepsia 54 (Suppl 7):77-85, 2013

18. Seegmüller C, Deonna T, Dubois CM, Valenti-Hirsch MP, Hirsch E, Metz-Lutz MN, et al: Long-term outcome after cognitive and behavioral regression in nonlesional epilepsy with continuous spike-waves during slow-wave sleep. Epilepsia 53:1067-1076, 2012

19. Tassinari CA, Cantalupo G, Rios-Pohl L, Giustina ED, Rubboli G: Encephalopathy with status epilepticus during slow sleep: “the Penelope syndrome.” Epilepsia 50 (Suppl 7):4-8, 2009

20. Tassinari CA, Dravet C, Roger J: ESES: encephalopathy related to electrical status epilepticus during slow sleep, in Proceedings of the 9th Congress International Federation of EEG and Clinical Neurophysiology. Amsterdam: Elsevier, 1977, pp 529-530

21. Tassinari CA, Rubboli G, Volpi L, Meletti S, d'Orsi G, Franca M, et al: Encephalopathy with electrical status epilepticus during slow sleep or ESES syndrome including the acquired aphasia. Clin Neurophysiol 111 (Suppl 2):S94-S102, 2000

22. Veggiotti P, Beccaria F, Papalia G, Termine C, Piazza F, Lan- zi G: Continuous spikes and waves during sleep in children with shunted hydrocephalus. Childs Nerv Syst 14:188-194, 1998

23. Wieser HG, Blume WT, Fish D, Goldensohn E, Hufnagel A, King D, et al: ILAE Commission Report. Proposal for a new classification of outcome with respect to epileptic seizures following epilepsy surgery. Epilepsia 42:282-286, 2001

\section{Disclosures}

Dr. Limbrick has received support from Medtronic Inc. and Karl Storz Inc. for non-study-related clinical or research effort.

\section{Author Contributions}

Conception and design: Jeong, Smyth, Bertrand. Acquisition of data: Jeong, Strahle, Vellimana, Smyth, Bertrand. Analysis and interpretation of data: all authors. Drafting the article: Jeong. Critically revising the article: Jeong, Strahle, Limbrick, Smyth, Bertrand. Reviewed submitted version of manuscript: all authors. Approved the final version of the manuscript on behalf of all authors: Jeong.

\section{Supplemental Information Previous Presentations}

Portions of this work were presented in abstract form and oral presentation form at the 44th Annual Meeting of the AANS/CNS Joint Section on Pediatric Neurosurgery held in Seattle, Washington, on December 8-11, 2015.

\section{Correspondence}

Anna Jeong, Department of Neurology, Box 8111, Washington University School of Medicine, 660 South Euclid Ave., St. Louis, MO 63110. email: jeonga@neuro.wustl.edu. 